\title{
Cell biological mechanisms regulating chick neurogenesis
}

\author{
IOANNIS KASIOULIS and KATE G. STOREY* \\ Division of Cell \& Developmental Biology, School of Life Sciences, University of Dundee, UK
}

\begin{abstract}
Signalling pathways that regulate neural progenitor proliferation and neuronal differentiation have been identified. However, we know much less about how transduction of such signals is regulated within neuroepithelial cells to direct cell fate choice during mitosis and subsequent neuronal differentiation. Here we review recent advances in the experimentally amenable chick embryo, which reveal that this involves association of signalling pathway components with cell biological entities, including mitotic centrosomes and ciliary structures. This includes changing centrosomal localization of protein kinase $A$, which regulates Sonic hedgehog signalling and so neural progenitor status, and Mindbomb1, a mediator of Notch ligand activation, which promotes Notch signalling in neighbouring cells, and so is active in presumptive neurons. We further review cell biological events that underlie the later step of neuronal delamination, during which a newborn neuron detaches from its neighbouring cells and undergoes a process known as apical abscission. This involves inter-dependent actin and microtubule dynamics and includes dissociation of the centrosome from the ciliary membrane, which potentially alters the signalling repertoire of this now post-mitotic cell. Open questions and future directions are discussed along with technological advances which improve accuracy of gene manipulation, monitoring of protein dynamics and quantification of cell biological processes in living tissues.
\end{abstract}

KEY WORDS: Notch signalling, Shh signalling, apical abscission, neuronal delamination, centrosome, primary cilium

\section{Introduction}

Neurogenesis involves the regulated production of neurons. New born neurons then change shape and may migrate to new positions as they extend an axon and ultimately form the connections that underlie the functioning nervous system. The spatial and temporal control of neurogenesis determines the size of the nervous system and regional differences in such regulation play a primary role in the generation of the characteristic architecture of this tissue. The central nervous system is induced early in development and is first morphologically manifest in the chick embryo as a plate-like region of columnar epithelium surrounding the late stage primitive streak (Duval, 1889) - the so-called neural plate. As the notochord emerges from the rostral tip of the primitive streak, defining the ventral midline of the embryo, this early neuroepithelium begins the process of primary neurulation (Schoenwolf and Smith, 1990). This involves rolling up of the neural plate to form the neural tube (Fig. 1A). It is at this time that the pseudostratified organisation of the neuroepithelium becomes apparent. Progenitor cells within the neural tube adopt an elongated shape with membrane contacts at both the outer basal and inner apical (ventricular) surfaces (Langman et al., 1966) (Fig. 1B). The nuclei of neuroepithelial cells transit back and forth along the apico-basal axis as they progress through the cell cycle, undergoing mitosis at the ventricular surface and returning to the basal side of the cell during the G1 phase. There, they either continue in the cell cycle, re-entering S-phase and moving apically to divide again, or exit as they commence neuronal differentiation (Sauer, 1935) (Fig. 1B). As these cells are not synchronised in the cell cycle, this movement, known as interkinetic nuclear migration, confers the apparent layered structure characteristic of pseudostratified epithelia (Langman et al., 1966, Sauer, 1935). In the early neural tube, cells largely undergo symmetric divisions, which give rise to daughter cells that both continue as progenitors (progenitor-progenitor, PP divisions). At later stages, asymmetric divisions generate daughter cells that adopt different fates, either a progenitor or a neuron (progenitor-neuron, PN) with progenitor cells in such divisions often being referred to as neural stem cells as they continue to divide like their parent cell (Gotz and Huttner, 2005, McConnell, 1995, Rakic, 1995). The first terminal symmetric (neuron-neuron NN) divisions also begin to appear at relatively early stages in the chick neural tube (Wilcock et al., 2007).

Abbreviations used in this paper: AJ, adherens junction; Mib1, mindbomb1; PKA, protein kinase A; Shh, sonic hedgehog; Smo, smoothened.

*Address correspondence to: Kate G. Storey. Division of Cell \& Developmental Biology, School of Life Sciences, University of Dundee, Dundee, UK. Tel: +44 (0) 1382 385691. e-mail: k.g.storey@dundee.ac.uk - web: http://www.lifesci.dundee.ac.uk/people/kate-storey - (D) http://orcid.org/0000-0003-3506-1287 
Neuroepithelial cells display strong apico-basal polarity (Fig. $1 \mathrm{C})$. The basal side of these cells is characterised by localised beta-1-integrin expression (Long et al., 2016) while the apicolateral membrane possesses cadherin-based adherens junctions (AJ) (Afonso and Henrique, 2006, Dady et al., 2012, Hatta et al., 1987, Hatta and Takeichi, 1986) (Fig. 1C). AJ are associated with an acto-myosin cable and proteins such as ZO-1, which is typically linked to tight junctions in the early chick embryo (AakuSaraste et al., 1996). This junctional belt abuts the apical-most membrane, which contains the cortex-associated apical polarity complex (Afonso and Henrique, 2006) and an apical centrosome which nucleates the axonemal microtubules of the primary cilium (Hinds and Ruffett, 1971) (Fig. 1C). Newborn neurons must detach from neighbouring cells at the apical/ventricular surface in order to move out of this proliferative zone and commence the morphological re-organisation that underpins neuronal differentiation. This apical detachment process is known as delamination. It involves downregulation of AJ proteins such as $\mathrm{N}$-cadherin and subsequent withdrawal of the cell-process from the apical surface, re-orientation of the cell body, neuron migration, axonogenesis and growth cone formation (Singh and Solecki, 2015). These steps have been described in detail for the earliest born neurons in the chick spinal cord (Wilcock et al., 2007).

The chick embryo has been used extensively to study neurogenesis for a variety of reasons. Fertilised eggs are readily available and because the embryo sits flat on top of the egg yolk, the developing neural tube can be easily accessed, labelled and manipulated. For instance, in ovo electroporation allows introduction of plasmids in to cells of the neural tube to express genes of interest (Itasaki et al., 1999) Electroporation conditions can be fine-tuned to target only a few scattered cells, allowing the cell behaviour of individual

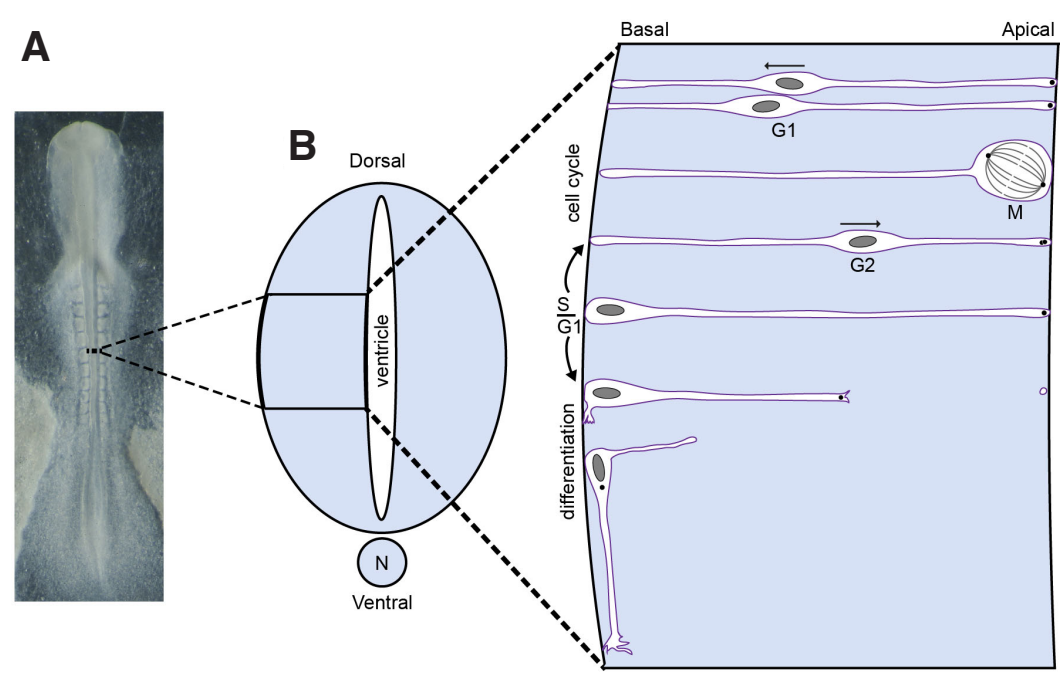

C

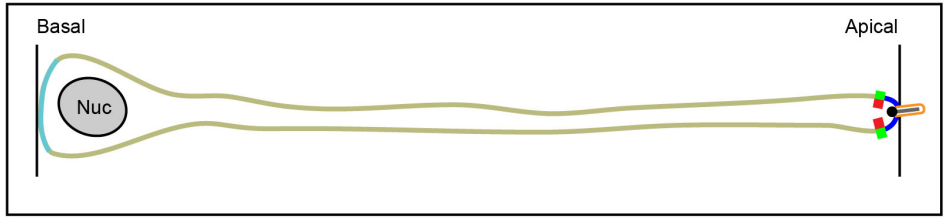

- $\beta$ 1-integrin Acto-myosin $\square \mathrm{N}$-Cadherin Centrosome

Apical polarity complex Ciliary membrane Ciliary axoneme cells to be monitored and quantified. The chicken embryo is also resilient, rapidly resuming development after transient reduction to room temperature and so is amenable to approaches such as embedding and sectioning of electroporated neural tube for longterm live tissue imaging (Das et al., 2012). The chick neural tube and the developing spinal cord in particular have therefore been used extensively to gain insights into the cell behaviours and protein dynamics that regulate neurogenesis.

Initial live imaging studies of chick neurogenesis have focused on characterisation of cell cycle parameters and cell division modes, e.g. (Morin et al., 2007, Peyre et al., 2011, Saade et al., 2013, Spear and Erickson, 2012, Wilcock et al., 2007) including regulation of mitotic spindle orientation (see (di Pietro et al., 2016)). In this short review, we discuss recent studies that advance our understanding of cell biological mechanisms which underpin the activities of key signalling pathways that regulate neurogenic cell fate, and that orchestrate neuronal delamination.

\section{Centrosomes as signalling hubs}

A striking feature of mitosis is the asymmetric nature of the two centrosomes that nucleate the mitotic spindle (Fig. 2). The centrosome is composed of two centrioles, one is the original maternal centriole and the other its daughter. When a cell embarks on a new cell cycle each centriole replicates to produce a new daughter and following mitosis each cell then inherits either the original maternal centriole or its daughter, each with their associated new daughter centrioles. The original maternal centrosome and daughter centrosome have distinct ultrastructure and molecular composition (Delattre and Gonczy, 2004, Nigg and Raff, 2009). A unique feature of the maternal centrosome is its distal appendages, which can serve to anchor the primary cilium. Importantly, such asymmetries have been linked to cell fate choice (Reina and Gonzalez, 2014). In NP divisions of the mouse cortex, the original maternal centrosome is retained by the progenitor cell, while the prospective neuron contains the daughter centrosome (Wang et al., 2009). Furthermore, this has been correlated with the retention of a ciliary membrane remnant in the progenitor cell, which is then pre-disposed to Sonic hedgehog (Shh) signalling activity (Paridaen et al., 2013). In addition, loss of the

Fig. 1. Neural tube architecture in the early chick embryo. (A) Ten somite chicken embryo (Hamburger and Hamilton stage 10). (B) Schematic transverse section through the neural tube and the notochord in the spinal cord region, (N) notochord; Neuroepithelial cells have apical/ventricular and basal connections and an apical primary cilium (only centrosome indicated here) and their nuclei transit along the apico-basal axis (interkinetic nuclear migration) during the cell cycle, with cells undergoing mitosis at the apical surface. Daughter cells that exit the cell cycle and are about to delaminate (in G1) have a basally located cell body and long cell-process that contacts the apical surface. These cells lose contact with neighbouring cells at the apical surface and undergo apical abscission leaving behind apical membrane (including ciliary membrane) as the cell-process (including the centrosome) is withdrawn. The newborn neuron will then re-polarise, projecting an axon, with a navigating growth cone at its tip. (C) Single neuroepithelial cell with basally located nucleus (Nuc) and positon of apical and basal proteins and primary cilium indicated. 


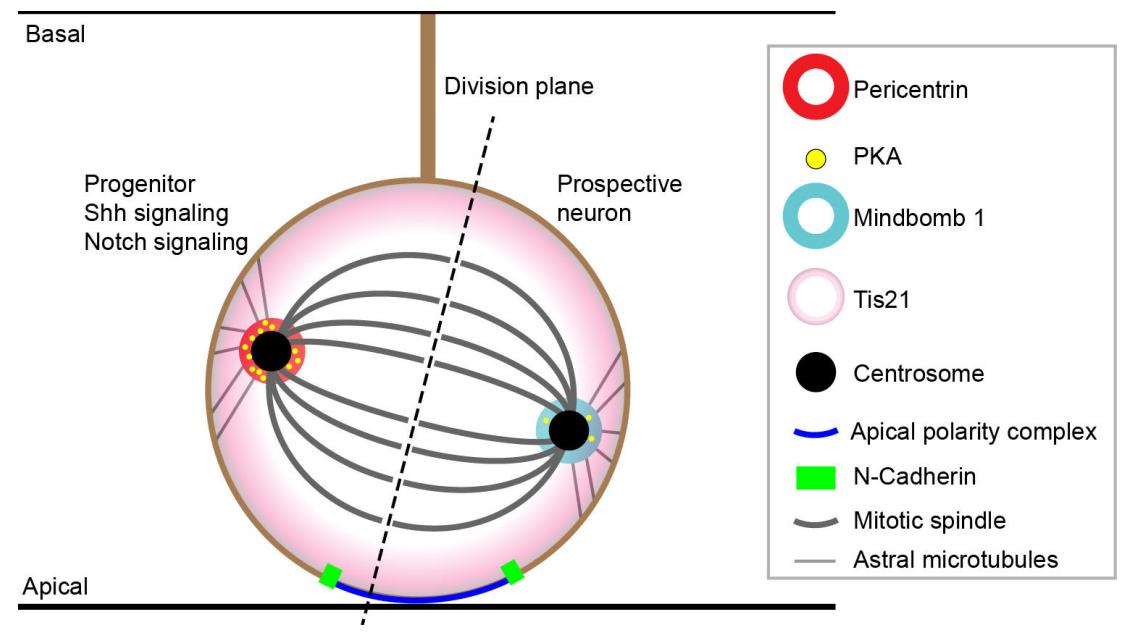

Fig. 2. The centrosome as a signalling hub. Asymmetric division of a neuroepithelialTis $21^{+}$ cell resulting in generation of a progenitor and a prospective neuron. The daughter cell inheriting the most apical cell membrane ( $N$-cadherin, apical polarity complex) becomes the neuron and its centrosome is enriched with Mindbomb 1, ultimately leading to the activation of Notch signalling in the neighbouring cell which maintains its progenitor cell state. Conversely, the daughter cell that inherits the basal membrane/process remains as a progenitor and its centrosome is pericentrin and PKA enriched leading to elevated Shh signalling.

mature (maternal) centrosome associated protein Ninein leads to depletion of the progenitor pool (Wang et al., 2009). These inherent centrosomal differences must clearly be overcome for cells to undergo symmetric divisions that generate two progenitors. Recent findings in the chick embryo have now begun to reveal how this is achieved by signalling pathways which promote neural progenitor proliferation (Saade et al., 2017, Tozer et al., 2017).

\section{Regulation of Sonic Hedgehog signalling via the centrosome}

Shh signalling promotes progenitor-generating (PP) divisions in the chick neuroepithelium (Cayuso et al., 2006). However, the cell biological mechanisms involved in the regulation of this pathway in this context are just beginning to be elucidated. In the absence of Shh, the transmembrane protein Patched 1 blocks the translocation of another transmembrane protein known as Smoothened (Smo) into the primary cilium, resulting in the cilia-localised transcription factors Gli2 and Gli3 being cleaved into their repressor forms that inhibit gene expression when they are imported into the nucleus. Upon Shh binding to Patched 1, inhibition on Smo is released and this protein then translocates into the primary cilium, blocks proteolysis of the Gli proteins that in turn function as transcriptional activators and facilitate expression of their target genes (Louvi and Grove, 2011). Protein kinase $A(P K A)$ also plays a role in regulating Gli activity by phosphorylating Gli proteins at 6 sites, rendering them inactive (Niewiadomski et al., 2014). Localisation of PKA to the centrosome is thought to block the PKA kinase activity, shifting the balance towards more activated Gli (Barzi et al., 2010, Saade et al., 2017). In a recent study, PKA was found symmetrically localised to both mitotic centrosomes in the early chick neuroepithelium where divisions are almost exclusively proliferative (Saade et al., 2017). At later stages, when asymmetric divisions predominate, PKA appeared asymmetrically localised, with high levels in only one centrosome (Fig. 2). Notably, neuroepithelial cells with activated
Shh, identified with the Gli-binding reporter construct Gli-BS-RFP (Sasaki et al., 1997), also showed symmetric centrosomal PKA. In contrast, in dividing cells where one daughter is committed to neurogenesis, identified by expression of the neurogenic marker Tis21 (lacopetti et al., 1999, Saade et al., 2013), PKA was asymmetrically localised at the centrosomes (Saade etal., 2017). Symmetric proliferative divisions are also characterised by the equal division of apical determinants such as Par3 and aPKC (Kosodo et al., 2004). Interestingly, in dividing Gli-active cells symmetric aPKC distribution was also correlated with symmetric PKA centrosomal localisation, while Gli inactive cells showed asymmetric aPKC distribution and PKA centrosomal localisation.

Importantly, the symmetric distribution of PKA in Shh responsive cells was attributed to upregulated expression of the centrosomal genes pericentrin and A-kinase anchoring protein 9 (AKAP9) (Saade et al., 2017), which are involved in docking PKA to the centrosome (Wong and Scott, 2004). Indeed, augmenting Shh activity by a dominant active form of Smo resulted in pericentrin over-expression and symmetric PKAcentrosomal localisation. Conversely, down-regulation of Shh by a dominant-negative form of the receptor Patched 1 resulted in reduced pericentrin expression and asymmetric PKA centrosomal localisation. Significantly, Shh signalling and pericentrin-mediated PKA docking are proposed to operate in a positive feedback loop: reduction in centrosome localised PKA (by mis-expression of a mutant PKA construct which effectively undocks PKA), reduced Gli transcriptional activation and induced the expression of the Tis21-Luc reporter, a marker of neurogenic progenitors and neurons (Saade et al., 2017). These findings therefore uncover a correlation between Shh activity and centrosome maturation that results in symmetric PKA centrosome docking, which in turn promotes Shh signalling and so neural progenitor proliferation. A key question for the future is how Shh signalling promotes expression of pericentin and other centrosomal genes, which appear not to be direct Gli targets (Saade et al., 2017). As addressed below, there may also be mechanisms to ensure Shh signalling loss as the centrosome matures in the differentiating neuron.

\section{Regulation of Notch signalling via the centrosome}

Centrosomal localization of a key mediator of Notch signalling has also recently been implicated in the regulation of neural progenitor cell fate. Notch signalling is necessary for the maintenance of progenitors in the central nervous system and mediates the cell selection process known as Lateral Inhibition, demonstrated in the developing chick spinal cord and retina (Henrique et al., 1995, Henrique et al., 1997) as well as in the murine radial glial cells (Pierfelice et al., 2011, Yoon et al., 2008). Notch transmembrane receptors in one cell are activated by the membrane localized ligands Delta or Jagged presented by an adjacent cell. Differentiating neurons express Notch ligands and so activate Notch signalling in neighbouring cells thereby keeping them in a progenitor cell state (Pierfelice et al., 2011). Mindbomb1 (Mib1) is a mono-ubiquitin ligase that regulates the trafficking and activation of Notch ligands 
and so the ability to promote Notch signalling in neighbouring cells (Itoh et al., 2003, Weinmaster and Fischer, 2011). Analysis of Mib1 localization in interphase neural progenitors revealed co-localisation with asymmetrically positioned centriolar satellite proteins centrosomal protein 131 (CEP131 or AZI1) and pericentriolar material 1 (PCM1) (Tozer at al 2017). However, these researchers found that Mib1 could display symmetric or asymmetric distribution in late mitosis; symmetric distribution being achieved by compensatory Mib1 from an additional Golgi-associated pool. By employing en face live imaging the distribution of Mib1-GFP and the fate of daughter cells was correlated. Symmetric centrosomal distribution of Mib1-GFP identified proliferative divisions (as daughter cells were seen to re-enter mitosis), while cells with asymmetric Mib1-GFP correlated with neurogenic divisions (Fig. 2). As previously demonstrated, biasing the division mode to neurogenic (apico-basally orientated) via Inscuteable-GFP mis-expression elevated Notch signalling in the basal (future progenitor) daughter cell (Das and Storey, 2012). Tozer et al., showed that displacing Mib1 from the centrosome of dividing cells mis-expressing Inscuteable-GFP now led to Notch activity in both daughter cells. This is interpreted to indicate that asymmetric centrosomal Mib1 localization is required in neurogenic divisions to allow the prospective neuron to inherit most of the Mib1 and so, after mitosis, be able to deliver higher levels of active Notch ligand to its sibling, which then remains undifferentiated.

Interestingly, Notch signalling can amplify the cellular response to Shh by promoting Smo localization to the primary cilium in interphase cells (Kong et al., 2015, Stasiulewicz et al., 2015). In the future, it might be interesting to assess whether such Notch activity also augments Shh signalling during mitosis, perhaps influencing centrosomal PKA localization and/or if Shh-mediated centrosome maturation, including pericentrin upregulation affects Mib1 localization.

\section{Dismantling the primary cilium on neuronal delamination}

As differentiating neurons leave the cell cycle such cells must experience a change in their reception, transduction, or response to mitogenic signals. We have seen that centrosomal localization of Mib1 or PKA can influence this process. The striking dissociation of the centrosome and ciliary membrane observed just prior to neuronal delamination in the chick spinal cord (Das and Storey, 2014) may provide a further mechanism for sharp attenuation of such signals (Fig. 3A). Indeed, the apical primary cilium of cells poised to delaminate (identified by early neuronal marker, Tuj1) exhibits the hallmarks of active Shh signalling, with localisation of both Gli2 and Smo within the cilium (Das and Storey, 2014). Thus, although loss of centrosomal PKA may reduce Gli activity in the future neuron during mitosis, dismantling the primary cilium in the newborn neuron may further serve to curtail Shh signalling as the centrosome matures. Further details of primary cilium dissociation remain to be elucidated. For example, it is as yet unclear whether microtubules of the ciliary axoneme are shed along with the ciliary membrane or retained by the centrosome in the withdrawing cell-process of the newborn neuron. The molecular mechanisms underlying this dissociation are also not well understood, but might involve microtubule severing proteins such as katanin or spastin (Lohret et al., 1998). If a remnant of the ciliary axoneme is retained it would be interesting to determine whether this is critical for later functions of the centrosome in the newborn neuron.

Interestingly, in the zebrafish retina most, but not all, differentiating neuroblasts (identified in a live imaging assay cells withdrawing their apical cell-process) lose Arl13b-GFP expressing ciliary membrane (Lepanto et al., 2016). This may indicate that distinct types of neuron regulate primary cilia composition differently and/or that there are species specific differences in this process.
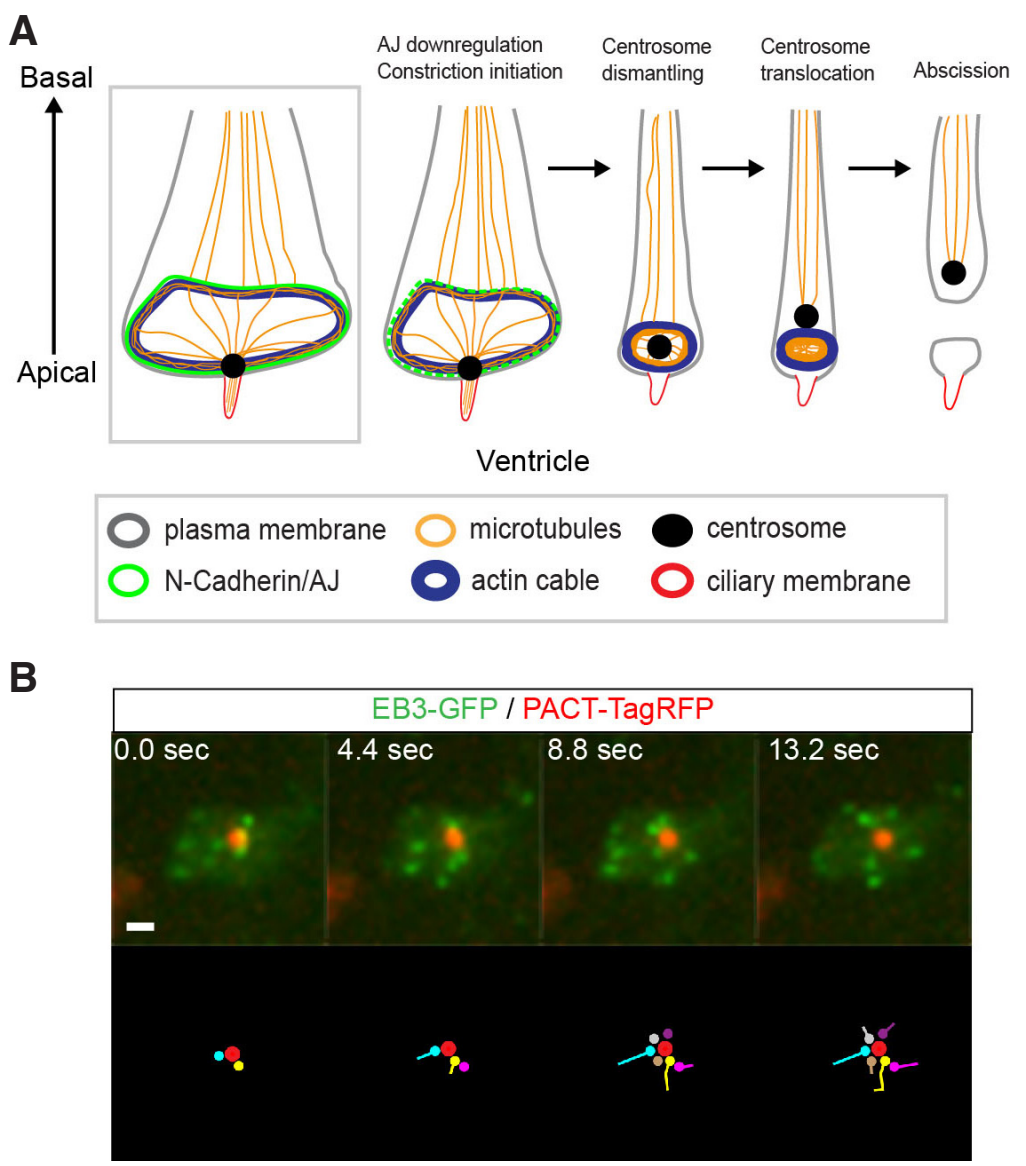

Fig. 3. Architecture of the neuroepithelial apical end-foot and steps leading to neuronal delamination. (A) The apico-lateral membrane of neuroepithelial cells is characterised by the presence of cadherin-based adherens junctions connected to the acto-myosin cable. A proportion of centrosome-nucleated microtubules extend to the cell periphery where they bend and grow along the actin cable, in a wheel-like configuration. The apical centrosome also nucleates microtubules which extend basally towards the nucleus as well as axonemal microtubules of the primary cilium. Apical abscission commences with the downregulation of $\mathrm{N}$-cadherin based adherens junctions and the constriction of the acto-myosin ring. The apical actin and microtubule cytoskeleton acquires a tunnel-like configuration and the centrosome dismantles from the ciliary membrane (the fate of axonemal microtubules is yet to be determined). The centrosome moves basally and the actin/microtubule condensation continues. Finally, membrane scission takes place leaving behind a particle that contains the ciliary and apical membranes; (B) The centrosome llabelled with PACT-TagRFP) of the apically localised primary cilium functions as the microtubule organising centre. Growing tip of microtubules (labelled with EB3-GFP) extend to the cell periphery; lower panel trajectories of EB3-GFP comets over time. Scale bar, $1 \mu \mathrm{m}$. 
A further caveat is that Arl13b mis-expression, which can lead to overgrowth of primary cilia (Lu et al., 2015), prevents timely disassembly preceding delamination in some contexts. Another approach might be to monitor ciliary length by fluorescent labelling of a member of the heterotrimeric kinesin-2 complex, such as Kif3A, which directly binds the axomene (Pazour and Rosenbaum, 2002). Overall, shedding and the rapid regrowth of the ciliary membrane in delaminating neurons (observed in zebrafish retina (Lepanto et al., 2016) and in chick spinal cord (KGS and Raman Das, unpublished) may serve not only to ensure cessation of Shh signalling, but may also provide an opportunity to make new ciliary membrane, which could be invested with a distinct set of receptors and signalling components appropriate for new tasks, such as axon growth and guidance.

In summary, regulation of Notch and Shh signalling involving mitotic centrosomes orchestrates neurogenic cell fate assignment, while dissociation of the primary cilium may facilitate neuronal differentiation by dismantling apparatus underpinning the processing of Shh pathway components.

\section{Initiating neuronal delamination: regulation of adherens junctions}

An important initial step in neuronal delamination is detachment from the apical surface. To do this, differentiating neurons need to lose the adhesive sub-apical N-cadherin-containing AJs which connect neighbouring epithelial cells (Meng and Takeichi, 2009, Miyamoto et al., 2015) (Fig. 3A). Mis-expression of N-cadherin in the chick neural tube inhibited cell detachment and cell-process withdrawal (Das and Storey, 2014). Similarly, in the quail neural tube $\mathrm{N}$-cadherin mis-expression blocked neural crest cellemigration (Shoval et al., 2007). Conversely, mis-expression of a dominant negative $\mathrm{N}$-cadherin construct lacking its extracellular domain in the zebrafish retina (Wong et al., 2012) or chick neural tube (Rousso et al., 2012) resulted in cell delamination and ectopic positioning of neurons. Furthermore, an N-cadherin conditional knock-out in the mouse cortex exhibited loss of AJs and scattered mitotic and post-mitotic cells throughout this tissue (Kadowaki et al., 2007). These experiments indicate that investigating $\mathrm{N}$-cadherin regulation will inform our understanding of neuronal delamination.

In the chick spinal cord, regulation of $\mathrm{N}$-cadherin is mediated positively by the transcription factor Sox2 (Bylund et al., 2003, Graham et al., 2003, Matsumata et al., 2005) and negatively by the forkhead transcription factors Foxp2 and Foxp4 (Rousso et al., 2012). The induction of these Foxp genes by rising levels of the proneural gene Neurog2 then elicits neuronal delamination (Rousso et al., 2012). Mis-expression of these Foxp transcription factors in the chick neural tube resulted in rapid loss of $\mathrm{N}$-cadherin, cell delamination and accumulation of differentiating neurons adjacent to the apical surface. This further involved associated loss of $\mathrm{N}$-cadherin protein, accompanied by depletion of other AJ components such as $\beta$-catenin as well as disruption of the subapical actin cable (Rousso et al., 2012). Conversely, knock down of Foxp4 alone or in combination with Foxp2 resulted in increased $\mathrm{N}$-cadherin transcripts and protein at AJs, and a reduction in differentiating cells. Generation of Foxp4 gene-trap and knockout mice further demonstrated conservation of the role for Foxptranscription factors in neurogenesis (Rousso et al., 2012). Other members of the forkhead transcription factor family, such as FoxD3 and FoxQ1 also exhibit an ability to repress cadherins (Cheung et al., 2005, Feuerborn et al., 2011), underlining the importance of transcriptional control of this key AJ protein in the regulation of epithelial cell behaviour. The regulation of cadherin protein transport and turnover are, however, also likely to fine tune cell-cell adhesion and influence cell delamination.

Indeed, plasmid driven $\mathrm{N}$-cadherin protein is lost from cells co-mis-expressing Neurog2 in the chick neuroepithelium, indicating that mechanism(s) other than transcription downregulation of endogenous $\mathrm{N}$-cadherin can operate to drive neuronal differentiation (Das and Storey, 2014). Some insight into this comes from recent work in the chick neuroepithelium, where rapid loss of $\mathrm{N}$-cadherin at AJs was observed following depolymerisation of microtubules or actin, using nocodazole and latrunculin-A, respectively (Kasioulis et al., 2017). Indeed, there is evidence that stable $\mathrm{N}$-cadherin maintenance at the AJs depends on microtubule transport and controlled endocytosis. In Kap3 knock-out mice and mouse embryonic fibroblasts, $\mathrm{N}$-cadherin and $\beta$-catenin transport are dependent on the KIF3 motor (Teng et al., 2005). In cultured cells, $\mathrm{N}$-cadherin transport to the cell cortex is also dependent on microtubule-mediated kinesin transport and additionally required an intact actin cytoskeleton (Mary et al., 2002). The involvement of actin in this process is further supported by the precocious delamination phenotype in the cortex of mice following conditional knockout of the RhoGTPase Cdc42, which regulates F-actin as well as affecting cell polarity complexes (Cappello et al., 2006). $\mathrm{F}$-actin depolymerisation can also enhance endocytosis from the AJ plasma membrane (Izumi et al., 2004). Together these findings suggest that microtubules and actin play roles in cadherin transport and turn over in the neuroepithelium and so support AJs.

\section{Apical abscission follows $\mathrm{N}$-cadherin downregulation}

Investigation of the steps leading to neuronal delamination following $\mathrm{N}$-cadherin downregulation has been advanced by development of live tissue imaging assays in the chick embryo (Das et al., 2012, Kasioulis et al., 2017, Peyre et al., 2011, Wilcock et al., 2007). These approaches readily allow plasmid transfection and monitoring of intra-cellular protein dynamics as individual cells undergo neurogenesis. This has revealed that delaminating neurons leave behind their apical tip as they detach from the apical surface. This new form of cell sub-division has been called apical abscission (Das and Storey, 2014). As noted above final detachment from the apical surface is preceded by dismantling of the primary cilium. This involves shedding of the ciliary membrane (identified by Arl13b expression) which is included in the abscised particle along with apical membrane expressing apical cell polarity marker aPKC, while the withdrawing cell-process retains the centrosome. Apical abscission therefore involves an abrupt loss of apical polarity, as well as dismantling of the primary cilium (Das and Storey, 2014).

Recent work has now further addressed the role and regulation of microtubules during neuronal delamination. High-resolution imaging revealed a striking wheel-like microtubule organisation in the apical end-foot of neuroepithelial cells (Kasioulis et al., 2017) (Fig. 3 A,B). This apical microtubule configuration was conserved across species and CNS regions, being found in the forebrain and spinal cord of chick and mouse embryos (Kasioulis et al., 2017). A similar apical microtubule arrangement has also been reported 
in kidney epithelial and cochlear cells (Bellett et al., 2009). Live imaging of microtubule nucleation using an EB3-GFP construct (to label growing microtubule plus-ends) further established that this structure emanated from the PACT-TagRFP labelled centrosome of the primary cilium (Fig. 3B). Importantly, the microtubule wheel rim aligned well with the actin cable in the neuroepithelial apical end-foot and monitoring of microtubule dynamics in delaminating neurons revealed a close correspondence with that of actin (Das and Storey, 2014, Kasioulis et al., 2017).

Exploiting the accessibility of these live imaging assays for the introduction of small molecules it has also been possible to demonstrate that neuronal delamination requires both actin and microtubules. Exposure to blebbistatin (an inhibitor of myosin motor function) (Kovacs et al., 2004) or ML-7 (an inhibitor of the myosin kinase MLCK that phosphorylates the small subunit of Myosin II complex) (Saitoh et al., 1987) inhibited neuronal delamination and ML-7 effects could be rescued by the co-expression of the constitutively active small Myosin II subunit MRLC2 (Das and Storey, 2014). Similarly, depolymerisation or stabilisation of microtubules (using nocodazole, Stathmin-GFP or taxol, (Jordan and Wilson, 1998, Jourdain et al., 1997) also inhibited neuronal delamination (Kasioulis et al., 2017). Notably, live imaging revealed that the configuration of both actin and microtubules changed dramatically during delamination forming a composite tunnel-like structure at the presumptive abscission site. Furthermore, experiments to test the effects of inhibition of microtubule growth on acto-myosin dynamics during delamination and conversely, inhibition of actomyosin contractility on microtubule dynamics during this process demonstrated that these are inter-dependent (Kasioulis et al., 2017).

So, while microtubules and actin support AJs between neuroepithelial cells, this then alters when newborn neurons undergo delamination, triggered by transcriptional downregulation of $N$ cadherin and so loss of AJs. In this new context, perhaps due to reduced linkage between the actin and AJs, the actin cable and aligned microtubule wheel condense and begin to form the abscission site. This step may have parallels with the molecular events that drive cytokinesis. Here RhoA-GTP is delivered to the cell equator via the central spindle and its activity results in the formation and contractility of the acto-myosin cable (Eggert et al., 2006, Piekny et al., 2005).

Crosstalk between these two cytoskeletal elements during neuronal delamination may also be mediated by one or more cross-linking proteins (Coles and Bradke, 2015). One such molecule is Drebrin, an actin binding protein (Ishikawa et al., 1994, Shirao et al., 1988), important for oculomotor neuron migration in the chicken embryo (Dun et al., 2012) and neuritogenesis in rat cortical neurons (Geraldo et al., 2008). Drebrin was identified as a microtubule-actin cross-linker based on mass spectrometry of GST-EB3 pulldowns of growth cone cytosol (Geraldo et al., 2008). Interestingly, Drebrin has also been identified as a direct Neurog2 target (Gohlke et al., 2008). In the neural tube of day 3 chick embryos, endogenous and mis-expressed Drebin localised at the apical end-feet and co-localised with the actin cable where polymerising microtubules and actin filaments may be physically linked. Short hairpin knock-down of Drebrin resulted in a reduction in delaminating neurons (Kasioulis et al., 2017). It is therefore plausible that Drebrin directs the EB3 bound growing microtubule tips along the apical actin cable and so orchestrates their interdependent dynamics during neuronal delamination.

\section{The role of centrosome during neuronal delamination}

Following dissociation of centrosome and ciliary membrane during delamination, the centrosome moves basally beyond the forming abscission site and is thus retained in the withdrawing cell-process of the differentiating neuron (Das and Storey, 2014). This translocation of the centrosome also depends on both dynamic microtubule growth and acto-myosin contractility: when cells poised to abscise are treated with taxol or ML-7, they display reduced delamination and the centrosome remains apically localised (Kasioulis et al., 2017). The basal movement of the centrosome appears to be a late step in the delamination process, as it transits through the tunnel-like condensing apical actin-microtubule configuration and a narrow membrane bridge just prior to abscission (Kasioulis et al., 2017). The centrosome may therefore play a central role in delamination, as cells with a narrow actin cable diameter (characteristic of differentiating cells) display active centrosomal-nucleated microtubule growth. To test the requirement for the centrosome in this process this organelle was compromised specifically in cells poised to delaminate using chromophore assisted-light inactivation (CALI); a phototoxic method that releases free oxygen radicals from a protein construct called KillerRed (Bulina et al., 2006), in this instance linked to the centrosome-associated PACT-domain sequence. Induction of local damage to the centrosome significantly reduced its microtubule nucleating potential and concomitantly reduced neuronal delamination compared to a control non-phototoxic construct (Kasioulis et al., 2017). This indicates that an intact centrosome is indeed integral to the neuronal delamination mechanism.

In summary, these new findings highlight a novel wheel-like apical microtubule configuration generated by the centrosome of the primary cilium in neuroepithelial cells. They further reveal that interaction between these apical microtubules and the actin cable are critical for retention of the centrosome and detachment of the newborn neuron from the apical surface. Apical microtubules serve other functions prior to neuronal delamination, including supporting AJs. A further intriguing possibility is that distinct microtubule populations, which make the apical wheel-like structure and juxtapose the actin cable or extend directly from the centrosome towards the basally located nucleus (Fig. 3A), transport distinct cargos. This might include Gli proteins that must travel to the sometimes-distant nucleus to effect Shh signalling.

\section{Future directions}

Experiments in the developing chick neural tube are providing new insights into the cell biological mechanisms that regulate neurogenesis. A key frontier of these studies lies in elucidating how developmental signalling is mediated and regulated by association of pathway components with cell biological entities, such as mitotic centrosomes and ciliary structures. Further understanding of the molecular basis of centrosomal localization of proteins such as Mib1 or PKA will be important in this regard. The phenomenon of apical abscission and associated dismantling of the primary cilium may represent a novel mechanism by which cells alter their signalling repertoire as they commence differentiation. It will be important to establish whether apical abscission is characteristic of all differentiating neurons and the extent to which it is conserved across species. It will also be interesting to determine whether 
abscised particles, which remain transiently at the ventricular surface, are taken up by other cells, as documented by (Dubreuil et al., 2007, Marzesco et al., 2005) and if these might then serve a further signalling role.

Techniques that enable more precise dissection of the mechanisms of neurogenesis are also being developed. These include finer spatial and temporal control of mis-expressed constructs, such as conditionally activated plasmids (Watanabe et al., 2007) and constructs driven by tissue and cell type specific promoters or enhancers (Saade et al., 2013). The use of transgenic chickens that express fluorescent reporters, e.g. (Rozbicki etal., 2015) may reduce the need for invasive procedures such as electroporation. Finally, application of TALENS and refined CRISPR-Cas9 approaches to manipulate gene expression in chicken embryos (Taylor et al., 2017, Zhang et al., 2017) may also facilitate investigation of the molecular mechanisms regulating neurogenesis. The continued development of super resolution and light sheet microscopy techniques is also improving the accuracy with which we can monitor protein dynamics over long periods with minimal perturbation of tissue homeostasis. This is allowing greater quantification of cell biological processes in live embryos and tissues and is opening the way to investigation of the biophysics of cell behaviour, supported by development of ever finer tools to measure forces/tension experienced by cells, which can influence protein localization and also gene expression.

\section{Acknowledgements}

We are grateful to Drs Aida Rodrigo-Albors and Alwyn Dady for critical comments on this manuscript. IK is supported by a Wellcome Trust Investigator Award to KGS WT102817AIA

\section{References}

AAKU-SARASTE, E., HELLWIG, A. and HUTTNER, W.B. (1996). Loss of occludin and functional tight junctions, but not ZO-1, during neural tube closure--remodeling of the neuroepithelium prior to neurogenesis. Dev Biol 180: 664-679.

AFONSO, C. and HENRIQUE, D. (2006). PAR3 acts as a molecular organizer to define the apical domain of chick neuroepithelial cells. J Cell Sci 119: 4293-4304.

BARZI, M., BERENGUER, J., MENENDEZ, A., ALVAREZ-RODRIGUEZ, R. and PONS, S. (2010). Sonic-hedgehog-mediated proliferation requires the localization of PKA to the cilium base. J Cell Sci 123: 62-69.

BELLETT, G., CARTER, J.M., KEYNTON, J., GOLDSPINK, D., JAMES, C., MOSS, D.K. and MOGENSEN, M.M. (2009). Microtubule plus-end and minus-end capture at adherens junctions is involved in the assembly of apico-basal arrays in polarised epithelial cells. Cell Motil Cytoskeleton 66: 893-908.

BULINA, M.E., CHUDAKOV, D.M., BRITANOVA, O.V., YANUSHEVICH, Y.G., STAROVEROV, D.B., CHEPURNYKH, T.V., MERZLYAK, E.M., SHKROB, M.A., LUKYANOV, S. and LUKYANOV, K.A. (2006). A genetically encoded photosensitizer. Nat Biotechnol 24: 95-99.

BYLUND, M., ANDERSSON, E., NOVITCH, B.G. and MUHR, J. (2003). Vertebrate neurogenesis is counteracted by Sox1-3 activity. Nat Neurosci 6: 1162-1168.

CAPPELLO, S., ATTARDO, A., WU, X., IWASATO, T., ITOHARA, S., WILSCHBRAUNINGER, M., EILKEN, H.M., RIEGER, M.A., SCHROEDER, T.T., HUTTNER, W.B. et al., (2006). The Rho-GTPase cdc42 regulates neural progenitor fate at the apical surface. Nat Neurosci 9: 1099-1107.

CAYUSO, J., ULLOA, F., COX, B., BRISCOE, J. and MARTI, E. (2006). The Sonic hedgehog pathway independently controls the patterning, proliferation and survival of neuroepithelial cells by regulating Gli activity. Development 133: 517-528.

CHEUNG, M., CHABOISSIER, M.C., MYNETT, A., HIRST, E., SCHEDL, A. and BRISCOE, J. (2005). The transcriptional control of trunk neural crest induction, survival, and delamination. Dev Cell 8: 179-192.

COLES, C.H. and BRADKE, F. (2015). Coordinating neuronal actin-microtubule dynamics. Curr Biol 25: R677-R691.
DADY, A., BLAVET, C. and DUBAND, J.L. (2012). Timing and kinetics of E- to Ncadherin switch during neurulation in the avian embryo. Dev Dyn241: 1333-1349.

DAS, R.M. and STOREY, K.G. (2012). Mitotic spindle orientation can direct cell fate and bias Notch activity in chick neural tube. EMBO Rep 13: 448-454.

DAS, R.M. and STOREY, K.G. (2014). Apical abscission alters cell polarity and dismantles the primary cilium during neurogenesis. Science 343: 200-204.

DAS, R.M., WILCOCK, A.C., SWEDLOW, J.R. and STOREY, K.G. (2012). Highresolution live imaging of cell behavior in the developing neuroepithelium. $J$ Vis Exp. (62), e3920, doi: $10.3791 / 3920$

DELATTRE, M. and GONCZY, P. (2004). The arithmetic of centrosome biogenesis. J Cell Sci 117: 1619-1630.

DI PIETRO, F., ECHARD, A. and MORIN, X. (2016). Regulation of mitotic spindle orientation: an integrated view. EMBO Rep 17: 1106-1130.

DUBREUIL, V., MARZESCO, A.M., CORBEIL, D., HUTTNER, W.B. and WILSCHBRAUNINGER, M. (2007). Midbody and primary cilium of neural progenitors release extracellular membrane particles enriched in the stem cell marker prominin-1. $J$ Cell Biol 176: 483-495

DUN, X.P., BANDEIRA DE LIMA, T., ALLEN, J., GERALDO, S., GORDON-WEEKS P. and CHILTON, J.K. (2012). Drebrin controls neuronal migration through the formation and alignment of the leading process. Mol Cell Neurosci 49: 341-350.

DUVAL, M.M. (1889). Atlas d'embryologie. Masson, Paris.

EGGERT, U.S., MITCHISON, T.J. and FIELD, C.M. (2006). Animal cytokinesis: from parts list to mechanisms. Annu Rev Biochem 75: 543-566.

FEUERBORN, A., SRIVASTAVA, P.K., KUFFER, S., GRANDY, W.A., SIJMONSMA, T.P., GRETZ, N., BRORS, B. and GRONE, H.J. (2011). The Forkhead factor FoxQ1 influences epithelial differentiation. J Cell Physiol 226: 710-719.

GERALDO, S., KHANZADA, U.K., PARSONS, M., CHILTON, J.K. and GORDONWEEKS, P.R. (2008). Targeting of the F-actin-binding protein drebrin by the microtubule plus-tip protein EB3 is required for neuritogenesis. Nat Cell Biol 10: 1181-1189.

GOHLKE, J.M., ARMANT, O., PARHAM, F.M., SMITH, M.V., ZIMMER, C., CASTRO, D.S., NGUYEN, L., PARKER, J.S., GRADWOHL, G., PORTIER, C.J. et al., (2008). Characterization of the proneural gene regulatory network during mouse telencephalon development. BMC Biol 6: 15.

GOTZ, M. and HUTTNER, W.B. (2005). The cell biology of neurogenesis. Nat Rev Mol Cell Biol 6: 777-788.

GRAHAM, V., KHUDYAKOV, J., ELLIS, P. and PEVNY, L. (2003). SOX2 functions to maintain neural progenitor identity. Neuron 39: 749-765.

HATTA, K., TAKAGI, S., FUJISAWA, H. and TAKEICHI, M. (1987). Spatial and temporal expression pattern of $\mathrm{N}$-cadherin cell adhesion molecules correlated with morphogenetic processes of chicken embryos. Dev Biol 120: 215-227.

HATTA, K. and TAKEICHI, M. (1986). Expression of N-cadherin adhesion molecules associated with early morphogenetic events in chick development. Nature 320 447-449.

HENRIQUE, D., ADAM, J., MYAT, A., CHITNIS, A., LEWIS, J. and ISH-HOROWICZ, D. (1995). Expression of a Delta homologue in prospective neurons in the chick. Nature 375: 787-790.

HENRIQUE, D., HIRSINGER, E., ADAM, J., LE ROUX, I., POURQUIE, O., ISHHOROWICZ, D. and LEWIS, J. (1997). Maintenance of neuroepithelial progenitor cells by Delta-Notch signalling in the embryonic chick retina. Curr Bio/7: 661-670.

HINDS, J.W. and RUFFETT, T.L. (1971). Cell proliferation in the neural tube: an electron microscopic and golgi analysis in the mouse cerebral vesicle. ZZellforsch Mikrosk Anat 115: 226-264.

IACOPETTI, P., MICHELINI, M., STUCKMANN, I., OBACK, B., AAKU-SARASTE, E. and HUTTNER, W.B. (1999). Expression of the antiproliferative gene TIS21 at the onset of neurogenesis identifies single neuroepithelial cells that switch from proliferative to neuron-generating division. Proc NatIAcad Sci USA 96: 4639-4644.

ISHIKAWA, R., HAYASHI, K., SHIRAO, T., XUE, Y., TAKAGI, T., SASAKI, Y. and KOHAMA, K. (1994). Drebrin, a development-associated brain protein from rat embryo, causes the dissociation of tropomyosin from actin filaments. $J$ Biol Chem 269: 29928-33.

ITASAKI, N., BEL-VIALAR, S. and KRUMLAUF, R. (1999). 'Shocking' developments in chick embryology: electroporation and in ovo gene expression. Nat Cell Biol 1: E203-E207.

ITOH, M., KIM, C.H., PALARDY, G., ODA, T., JIANG, Y.J., MAUST, D., YEO, S.Y., 
LORICK, K., WRIGHT, G.J., ARIZA-MCNAUGHTON, L. et al., (2003). Mind bomb is a ubiquitin ligase that is essential for efficient activation of Notch signaling by Delta. Dev Cell 4: 67-82.

IZUMI, G., SAKISAKA, T., BABA, T., TANAKA, S., MORIMOTO, K. and TAKAI, Y. (2004). Endocytosis of E-cadherin regulated by Rac and Cdc42 small G proteins through IQGAP1 and actin filaments. J Cell Biol 166: 237-248.

JORDAN, M.A. and WILSON, L. (1998). Use of drugs to study role of microtubule assembly dynamics in living cells. Methods Enzymol 298: 252-276.

JOURDAIN, L., CURMI, P., SOBEL, A., PANTALONI, D. and CARLIER, M.F. (1997). Stathmin: a tubulin-sequestering protein which forms a ternary T2S complex with two tubulin molecules. Biochemistry 36: 10817-10821.

KADOWAKI, M., NAKAMURA, S., MACHON, O., KRAUSS, S., RADICE, G.L. and TAKEICHI, M. (2007). N-cadherin mediates cortical organization in the mouse brain. Dev Biol 304: 22-33.

KASIOULIS, I., DAS, R.M. and STOREY, K.G. (2017). Inter-dependent apical microtubule and actin dynamics orchestrate centrosome retention and neuronal delamination. eLife 6: e26215.

KONG, J.H., YANG, L., DESSAUD, E., CHUANG, K., MOORE, D.M., ROHATGI, R., BRISCOE, J. and NOVITCH, B.G. (2015). Notch activity modulates the responsiveness of neural progenitors to sonic hedgehog signaling. Dev Cell 33: 373-387.

KOSODO, Y., ROPER, K., HAUBENSAK, W., MARZESCO, A.M., CORBEIL, D. and HUTTNER, W.B. (2004). Asymmetric distribution of the apical plasma membrane during neurogenic divisions of mammalian neuroepithelial cells. EMBO J 23: 2314-2324.

KOVACS, M., TOTH, J., HETENYI, C., MALNASI-CSIZMADIA, A. and SELLERS, J.R. (2004). Mechanism of blebbistatin inhibition of myosin II. J Biol Chem 279: 35557-35563.

LANGMAN, J., GUERRANT, R.L. and FREEMAN, B.G. (1966). Behavior of neuroepithelial cells during closure of the neural tube. J Comp Neurol 127: 399-411.

LEPANTO, P., DAVISON, C., CASANOVA, G., BADANO, J.L. and ZOLESSI, F.R. (2016). Characterization of primary cilia during the differentiation of retinal ganglion cells in the zebrafish. Neural Dev 11: 10.

LOHRET, T.A., MCNALLY, F.J. and QUARMBY, L.M. (1998). A role for kataninmediated axonemal severing during Chlamydomonas deflagellation. Mol Biol Cell 9: 1195-1207.

LONG, K., MOSS, L., LAURSEN, L., BOULTER, L. and FFRENCH-CONSTANT, C. (2016). Integrin signalling regulates the expansion of neuroepithelial progenitors and neurogenesis via Wnt7a and Decorin. Nat Commun 7: 10354.

LOUVI, A. and GROVE, E.A. (2011). Cilia in the CNS: the quiet organelle claims center stage. Neuron 69: 1046-1060.

LU, H., TOH, M.T., NARASIMHAN, V., THAMILSELVAM, S.K., CHOKSI, S.P. and ROY, S. (2015). A function for the Joubert syndrome protein Arl13b in ciliary membrane extension and ciliary length regulation. Dev Biol 397: 225-236.

MARY, S., CHARRASSE, S., MERIANE, M., COMUNALE, F., TRAVO, P., BLANGY, A. and GAUTHIER-ROUVIERE, C. (2002). Biogenesis of N-cadherin-dependent cell-cell contacts in living fibroblasts is a microtubule-dependent kinesin-driven mechanism. Mol Biol Cell 13: 285-301.

MARZESCO, A.M., JANICH, P., WILSCH-BRAUNINGER, M., DUBREUIL, V., LANGENFELD, K., CORBEIL, D. and HUTTNER, W.B. (2005). Release of extracellular membrane particles carrying the stem cell marker prominin-1 (CD133) from neural progenitors and other epithelial cells. J Cell Sci 118: 2849-2858.

MATSUMATA, M., UCHIKAWA, M., KAMACHI, Y. and KONDOH, H. (2005). Multiple $\mathrm{N}$-cadherin enhancers identified by systematic functional screening indicate its Group B1 SOX-dependent regulation in neural and placodal development. Dev Biol 286: 601-617.

MCCONNELL, S.K. (1995). Constructing the cerebral cortex: neurogenesis and fate determination. Neuron 15: 76176-76178.

MENG, W. and TAKEICHI, M. (2009). Adherens junction: molecular architecture and regulation. Cold Spring Harb Perspect Biol 1: a002899.

MIYAMOTO, Y., SAKANE, F. and HASHIMOTO, K. (2015). N-cadherin-based adherens junction regulates the maintenance, proliferation, and differentiation of neural progenitor cells during development. Cell Adh Migr 9: 183-192.

MORIN, X., JAOUEN, F. and DURBEC, P. (2007). Control of planar divisions by the G-protein regulator LGN maintains progenitors in the chick neuroepithelium. Nat Neurosci 10: 1440-1448.
NIEWIADOMSKI, P., KONG, J.H., AHRENDS, R., MA, Y., HUMKE, E.W., KHAN, S., TERUEL, M.N., NOVITCH, B.G. and ROHATGI, R. (2014). Gli protein activity is controlled by multisite phosphorylation in vertebrate Hedgehog signaling. Cell Rep 6: 168-181.

NIGG, E.A. and RAFF, J.W. (2009). Centrioles, centrosomes, and cilia in health and disease. Cell 139: 663-678.

PARIDAEN, J.T., WILSCH-BRAUNINGER, M. and HUTTNER, W.B. (2013). Asymmetric inheritance of centrosome-associated primary cilium membrane directs ciliogenesis after cell division. Cell 155: 333-344.

PAZOUR, G.J. and ROSENBAUM, J.L. (2002). Intraflagellar transport and ciliadependent diseases. Trends Cell Biol 12: 551-555.

PEYRE, E., JAOUEN, F., SAADAOUI, M., HAREN, L., MERDES, A., DURBEC, P. and MORIN, X. (2011). A lateral belt of cortical LGN and NuMA guides mitotic spindle movements and planar division in neuroepithelial cells. J Cell Biol 193: 141-154.

PIEKNY, A., WERNER, M. and GLOTZER, M. (2005). Cytokinesis: welcome to the Rho zone. Trends Cell Biol 15: 651-658.

PIERFELICE, T., ALBERI, L. and GAIANO, N. (2011). Notch in the vertebrate nervous system: an old dog with new tricks. Neuron 69: 840-855.

RAKIC, P. (1995). A small step for the cell, a giant leap for mankind: a hypothesis of neocortical expansion during evolution. Trends Neurosci 18: 383-388.

REINA, J. and GONZALEZ, C. (2014). When fate follows age: unequal centrosomes in asymmetric cell division. Philos Trans R Soc Lond B Biol Sci 369(1650): 20130466.

ROUSSO, D.L., PEARSON, C.A., GABER, Z.B., MIQUELAJAUREGUI, A., LI, S., PORTERA-CAILLIAU, C., MORRISEY, E.E. and NOVITCH, B.G. (2012). Foxpmediated suppression of $\mathrm{N}$-cadherin regulates neuroepithelial character and progenitor maintenance in the CNS. Neuron 74: 314-330.

ROZBICKI, E., CHUAI, M., KARJALAINEN, A.I., SONG, F., SANG, H.M., MARTIN, R., KNOLKER, H.J., MACDONALD, M.P. and WEIJER, C.J. (2015). Myosin-IImediated cell shape changes and cell intercalation contribute to primitive streak formation. Nat Cell Biol 17: 397-408.

SAADE, M., GONZALEZ-GOBARTT, E., ESCALONA, R., USIETO, S. and MARTI, E. (2017). Shh-mediated centrosomal recruitment of PKA promotes symmetric proliferative neuroepithelial cell division. Nat Cell Biol 19: 493-503.

SAADE, M., GUTIERREZ-VALLEJO, I., LE DREAU, G., RABADAN, M.A., MIGUEZ, D.G., BUCETA, J. and MARTI, E. (2013). Sonic hedgehog signaling switches the mode of division in the developing nervous system. Cell Rep 4: 492-503.

SAITOH, M., ISHIKAWA, T., MATSUSHIMA, S., NAKA, M. and HIDAKA, H. (1987). Selective inhibition of catalytic activity of smooth muscle myosin light chain kinase. J Biol Chem 262: 7796-7801.

SASAKI, H., HUI, C., NAKAFUKU, M. and KONDOH, H. (1997). A binding site for Gl proteins is essential for HNF-3beta floor plate enhancer activity in transgenics and can respond to Shh in vitro. Development 124: 1313-1322.

SAUER, F.C. (1935). Mitosis in the neural tube. J. Comp. Neurol. 62: 377-405.

SCHOENWOLF, G.C. and SMITH, J.L. (1990). Mechanisms of neurulation: traditional viewpoint and recent advances. Development 109: 243-270.

SHIRAO, T., KOJIMA, N., KATO, Y. and OBATA, K. (1988). Molecular cloning of a cDNA for the developmentally regulated brain protein, drebrin. Brain Res 464: 71-74.

SHOVAL, I., LUDWIG, A. and KALCHEIM, C. (2007). Antagonistic roles of full-length $\mathrm{N}$-cadherin and its soluble BMP cleavage product in neural crest delamination. Development 134: 491-501.

SINGH, S. and SOLECKI, D.J. (2015). Polarity transitions during neurogenesis and germinal zone exit in the developing central nervous system. Front Cell Neurosci 9: 62.

SPEAR, P.C. and ERICKSON, C.A. (2012). Apical movement during interkinetic nuclear migration is a two-step process. Dev Biol 370: 33-41.

STASIULEWICZ, M., GRAY, S.D., MASTROMINA, I., SILVA, J.C., BJORKLUND, M., SEYMOUR, P.A., BOOTH, D., THOMPSON, C., GREEN, R.J., HALL, E.A. et al., (2015). A conserved role for Notch signaling in priming the cellular response to Shh through ciliary localisation of the key Shh transducer Smo. Development 142: 2291-2303.

TAYLOR, L., CARLSON, D.F., NANDI, S., SHERMAN, A., FAHRENKRUG, S.C. and MCGREW, M.J. (2017). Efficient TALEN-mediated gene targeting of chicken primordial germ cells. Development 144: 928-934.

TENG, J., RAI, T., TANAKA, Y., TAKEI, Y., NAKATA, T., HIRASAWA, M., KULKARNI, A.B. and HIROKAWA, N. (2005). The KIF3 motor transports N-cadherin and 
organizes the developing neuroepithelium. Nat Cell Biol 7: 474-482.

TOZER, S., BAEK, C., FISCHER, E., GOIAME, R. and MORIN, X. (2017). Differential Routing of Mindbomb1 via Centriolar Satellites Regulates Asymmetric Divisions of Neural Progenitors. Neuron 93: 542 - 551.e4

WANG, X., TSAI, J.W., IMAI, J.H., LIAN, W.N., VALLEE, R.B. and SHI, S.H. (2009). Asymmetric centrosome inheritance maintains neural progenitors in the neocortex. Nature 461: 947-955.

WATANABE, T., SAITO, D., TANABE, K., SUETSUGU, R., NAKAYA, Y., NAKAGAWA S. and TAKAHASHI, Y. (2007). Tet-on inducible system combined with in ovo electroporation dissects multiple roles of genes in somitogenesis of chicken embryos. Dev Biol 305: 625-636.

WEINMASTER, G. and FISCHER, J.A. (2011). Notch ligand ubiquitylation: what is it good for? Dev Cell 21: 134-144.
WILCOCK, A.C., SWEDLOW, J.R. and STOREY, K.G. (2007). Mitotic spindle orientation distinguishes stem cell and terminal modes of neuron production in the early spinal cord. Development 134: 1943-1954.

WONG, G.K., BAUDET, M.L., NORDEN, C., LEUNG, L. and HARRIS, W.A. (2012) Slit1b-Robo3 signaling and $\mathrm{N}$-cadherin regulate apical process retraction in developing retinal ganglion cells. J Neurosci 32: 223-228

WONG, W. and SCOTT, J.D. (2004). AKAP signalling complexes: focal points in space and time. Nat Rev Mol Cell Biol 5: 959-970.

YOON, K.J., KOO, B.K., IM, S.K., JEONG, H.W., GHIM, J., KWON, M.C., MOON, J.S., MIYATA, T. and KONG, Y.Y. (2008). Mind bomb 1-expressing intermediate progenitors generate notch signaling to maintain radial glial cells. Neuron 58: 519-531.

ZHANG, Y., WANG, Y., ZUO, Q., LI, D., ZHANG, W., WANG, F., JI, Y., JIN, J., LU, Z., WANG, M. et al., (2017). CRISPR/Cas9 mediated chicken Stra8 gene knockout and inhibition of male germ cell differentiation. PLoS One 12: e0172207. 


\section{Further Related Reading, published previously in the Int. J. Dev. Biol.}

The surface ectoderm of the chick embryo exhibits dynamic variation in its response to neurogenic signals Vineeta-Bhasker Tripathi, Yasuo Ishii, Muhammad M. Abu-Elmagd and Paul J. Scotting

Int. J. Dev. Biol. (2009) 53: 1023-1033

https://doi.org/10.1387/ijdb.082780vt

Cellular dynamics and molecular control of the development of organizer-derived cells in quail-chick chimeras Jean-Baptiste Charrier, Martin Catala, Françoise Lapointe, Nicole Le Douarin and Marie-Aimée Teillet

Int. J. Dev. Biol. (2005) 49: 181-191

http://www.intjdevbiol.com/web/paper/041962jc

Retinal stem cells and regeneration

Ala Moshiri, Jennie Close and Thomas A. Reh

Int. J. Dev. Biol. (2004) 48: 1003-1014

http://www.intjdevbiol.com/web/paper/041870am

Notch activity is required to maintain floorplate identity and to control neurogenesis in the chick hindbrain and spinal cord Isabelle le Roux, Julian Lewis and David Ish-Horowicz

Int. J. Dev. Biol. (2003) 47: 263-272

http://www.intjdevbiol.com/web/paper/12755331

Early neurogenesis in Amniote vertebrates

N M Le Douarin

Int. J. Dev. Biol. (2001) 45: 373-378

http://www.intjdevbiol.com/web/paper/11291868

Complementary roles of the insulin family of factors and receptors in early development and neurogenesis

F De Pablo, C Alarcón, B Díaz, M García-De Lacoba, A López-Carranza, A V Morales, B Pimentel, J Serna and E J De la Rosa

Int. J. Dev. Biol. (1996) 40: S109-S110

http://www.intjdevbiol.com/web/paper/9087719

Transplantations of the chick eye anlage reveal an early determination of nasotemporal polarity

D Dütting and S U Meyer

Int. J. Dev. Biol. (1995) 39: 921-931

http://www.intjdevbiol.com/web/paper/8901194

5 yr ISI Impact Factor $(2016)=2.421$
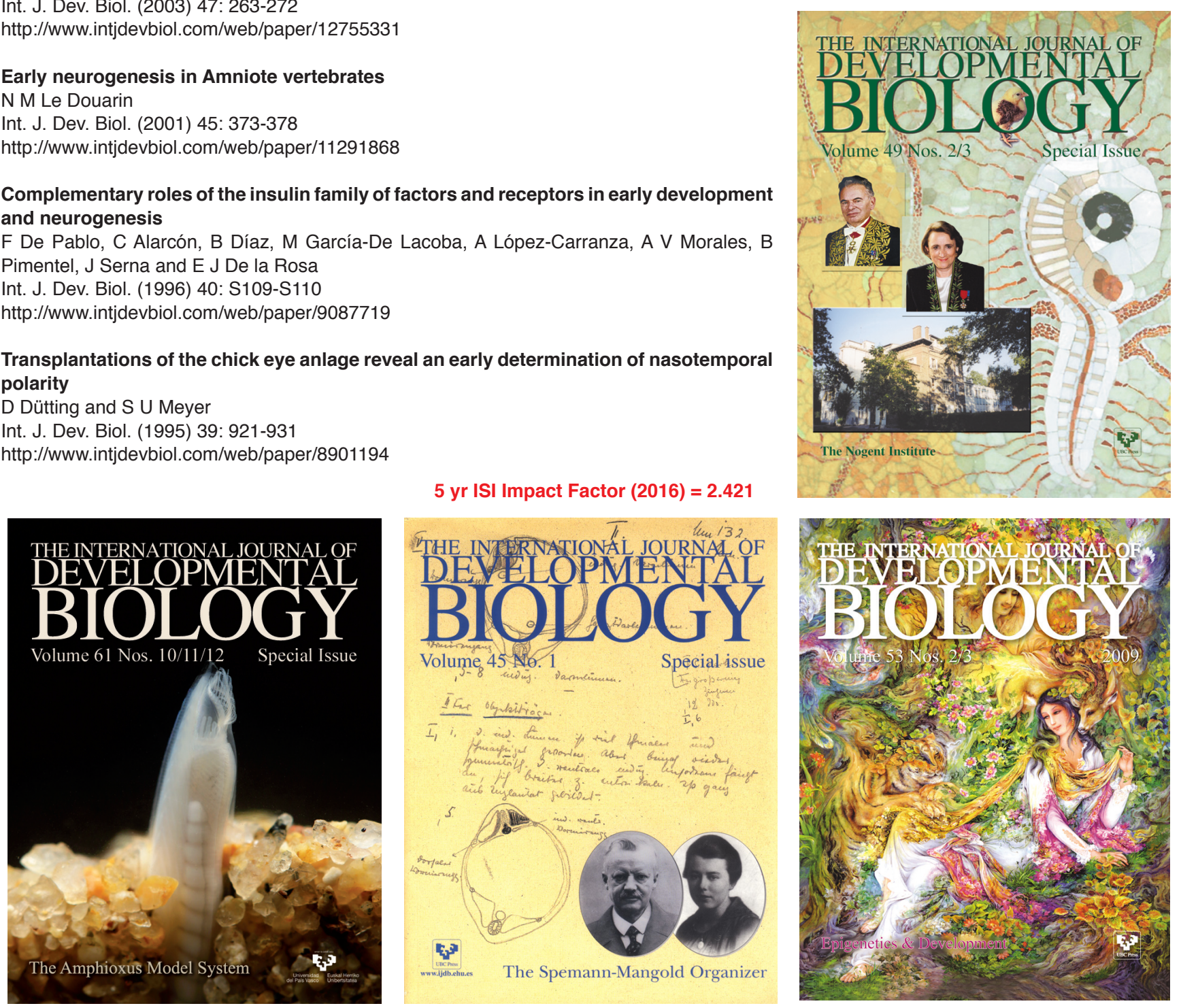